\title{
ARTIGO
}

$\mathrm{DOI}$

\section{A LITERATURA COMO DISPOSITIVO PARA EXPRESSÃO DE CRENÇAS RELIGIOSAS NO CONTEXTO ESCOLAR 1}

\author{
LITERATURE AS AN INSTRUMENT FOR EXPRESSION OF RELIGIOUS BELIEFS IN THE \\ SCHOOL CONTEXT
}

\section{LA LITERATURA COMO DISPOSITIVO PARA EXPRESIONES DE CRISIS RELIGIOSAS EN EL CONTEXTO ESCOLAR}

\author{
Elisângela Maura Catarino \\ Centro Universitário de Mineiros - Brasil \\ Marcelo Máximo Purificação \\ Centro Universitário de Mineiros - Brasil \\ Maria Luzia da Silva Santana \\ Universidade Federal de Mato Grosso do Sul - Brasil
}

\section{Resumo}

Esta pesquisa problematiza a literatura como dispositivo para a expressão de crenças religiosas na escola, tendo o objetivo de verificar se as crenças se manifestam no contexto escolar quando o estudante se depara com elementos da religiosidade nos textos literários. Para isso, foram realizadas observações numa turma do Terceiro Ano do Ensino Médio, que tinha vinte e nove estudantes frequentes, de uma escola pública localizada no entorno do Distrito Federal, no Estado de Goiás. Com fins de análise no presente texto, foram exploradas as falas de quatro estudantes, sendo um do sexo feminino e três do sexo masculino. Foi realizada observação in loco, das aulas da professora e das expressões dos estudantes durante o desenvolvimento do letramento literário, com as obras "Tenda dos Milagres" e "Tieta do Agreste", ambas de Jorge Amado. Foram registradas as falas dos estudantes e da professora relacionadas às temáticas crenças e religiosidade. Os dados desta pesquisa reafirmaram a importância da literatura como um dispositivo que contribui para que o estudante-leitor construa diferentes olhares em torno da religiosidade. Ao trabalhar com os livros citados o professor não poderá perder de vista que o processo de ensino e aprendizagem é permeado por elementos da historicidade e da cultura do estudante que se constitui - enquanto pessoa - na sua relação com os elementos culturais e sociais. Devido a sociedade brasileira ter variadas matrizes religiosas, nas aulas podem vir à tona choques

\footnotetext{
${ }^{1}$ Parte dos dados discutidos neste artigo estão disponíveis na tese de doutorado defendida pela primeira autora no Programa de Pós-Graduação em Ciências da Religião da Pontifícia Universidade Católica de Goiás.
} 
culturais ou conflitos religiosos. As crenças e diferentes religiosidades estão presentes no cotidiano da escola e têm implicações na leitura e interpretação das obras literárias. Este aspecto reafirma a ideia de que as crenças e a religiosidade não podem ser um tema ignorado, mas sim extensivamente trabalhado pelo professor como um elemento positivador da pluralidade cultural-religiosa existente no país.

Palavras-chave: Crenças. Literatura. Religiosidade.

\begin{abstract}
This research studies literature as a device for the expression of religious beliefs in school, trying to verify if the religious beliefs are shown in school context when the students are confronted with religious elements in literary texts. To reach this aim, observations were made in a group 29 frequent students of a third year of a High public school located near the Brazilian D.C. in the State of Goiás. As a research universe, were observed four students: a girl and three boys. On in loco observation of the teacher's classes and students' expressions during the development of the literature classes using "Tenda dos Milagres" and "Tieta do Agreste", both by the brazilian writer Jorge Amado. The statements of the students and the teacher related to beliefs and religiosity were registered. The obtained data showed the importance of literature as an instrument of contribution to the student-reader construct his different perspectives on religiosity. When working with the listed books, the teacher must reflect that teaching and learning process is made of historical and cultural elements that constitutes the student - as a person - in close relationship with his social reality. Brazilian society has various religious matrices; so, cultural clashes or religious conflicts can arise in the classroom very often. Beliefs and different religions are present in everyday classes and implicates directly in reading and interpretation of literary book. This aspect reaffirms the idea that beliefs and religiosity can't be ignored, but extensively addressed by the teacher as a positive element in dealing with religious diversity.
\end{abstract}

Keywords: Beliefs. Literature. Religiosity.

\title{
Resumen
}

Esta investigación problematiza la literatura como dispositivo para la expresión de creencias religiosas en la escuela, teniendo el objetivo de verificar si las creencias se manifiestan en el contexto escolar cuando el estudiante se depara con elementos de la religiosidad en los textos literarios. Para ello, se realizaron observaciones en una clase del Tercer Año de la Enseñanza Media, que tenía veintiocho estudiantes frecuentes, de una escuela pública ubicada en el entorno del Distrito Federal, en el Estado de Goiás. Con fines de análisis en el presente texto, se exploraron De cuatro estudiantes, siendo una de las mujeres y tres del sexo masculino. Se realizó una observación in loco, de las clases de la profesora y de las expresiones de los estudiantes durante el desarrollo del literal literario, con las obras "Tenda de los Milagros" y "Tieta do Agreste", ambas de Jorge Amado. Se registraron las palabras de los estudiantes y de la profesora relacionadas con las temáticas creencias y religiosidad. Los datos de esta investigación reafirmaron la importancia de la literatura como un dispositivo que contribuye a que el estudiante lector crea diferentes miradas en torno a la religiosidad. Al trabajar con los libros citados el 
profesor no podrá perder de vista que el proceso de enseñanza y aprendizaje está impregnado por elementos de la historicidad y de la cultura del estudiante que se constituye-como persona- en su relación con los elementos culturales y sociales. Debido a que la sociedad brasileña tiene variadas matrices religiosas, en las clases pueden surgir choques culturales o conflictos religiosos. Las creencias y diferentes religiosidades están presentes en el cotidiano de la escuela y tienen implicaciones en la lectura e interpretación de las obras literarias. Este aspecto reafirma la idea de que las creencias y la religiosidad no pueden ser un tema ignorado, sino ampliamente trabajado por el profesor como un elemento positivador de la pluralidad cultural-religiosa existente en el país.

Palabras clave: Creencias. Literatura. Religiosidad.

\section{Introdução}

As questões religiosas permeiam a vida em sociedade, sendo evidenciadas através das crenças em algum tipo de divindade. Os ritos e manifestações religiosas podem aparecer representadas em símbolos, palavras, nos discursos apresentados em diferentes contextos sociais, inclusive na instituição escolar. Na instituição escolar, os rituais da escola podem ser observados nos livros, na postura do educador, nos estudantes e na própria cultura escolar, a exemplo das orações coletivas realizadas semanalmente. Enquanto material pedagógico, observa-se que a literatura escolhida para trabalhar nas aulas e a forma como se lê podem evidenciar as crenças religiosas que são carregadas de significados e sentidos.

Falar de crenças religiosas não é uma tarefa fácil, principalmente quando levamos em consideração que existe uma gama de religiões e diferentes formas de manifestar a crença. Compreender ainda que as religiões participam e atuam sobre as diferentes ações sociais, por estarem diretamente ligadas à cultura é desafiante, principalmente quando se propõe problematizar as crenças no contexto escolar.

É relevante pontuar as diferenças entre crenças religiosas e religião. Segundo Abbagnano (1999) a religião é crença na garantia sobrenatural de salvação, e técnica destinada a obter e conservar essa garantia. O fato é que as religiões sempre estiveram presentes no pensamento e nas ações 
humanas, participando da construção histórico-cultural do mundo e do autoconhecimento dos indivíduos.

No entanto, a crença permeia campo mais amplo, não se restringindo apenas ao religioso, mas se coloca mais adiante. Pensar em crença religiosa é levar em conta o tipo de sociedade constituída nos dias de hoje e como essa sociedade vem se relacionando com sua religiosidade. Podemos crer em qualquer coisa à qual atribuímos valor e significado. Abbagnano (1999) afirma que, em um significado mais geral, a crença é atitude de quem reconhece como verdade uma proposição. Portanto, a adesão à validade de uma noção qualquer. Para o campo religioso, a crença pode pertencer ao domínio da fé, as assim chamadas confissões religiosas.

Hervieu-Leger (2008), em sua obra "O Peregrino e o convertido", constrói um panorama religioso mais difuso ainda. Aponta para uma "difusão do crê individualista, pela disjunção das crenças e das pertenças confessionais e pela diversificação de novas formas de expressões religiosas" (HERVIEU-LEGER, 2008, p. 8). Se temos uma sociedade difusa, as crenças religiosas também acabam acompanhando esse processo.

A autora ainda traz um olhar maior sobre o tema, colocando que "o que caracteriza o tempo atual não é a mera indiferença com respeito à crença, mas a perda de sua 'regulamentação' por parte das instituições tradicionais produtoras de sentido" (HERVIEU-LEGER, 2008, p. 9). Ou seja, as instituições religiosas não mantêm mais uma força soberana sobre seus fiéis, e esses, por sua vez, buscam diferentes sentidos ao pensamento religioso, não se prendendo a um único modelo nem a uma única forma de crença.

A religiosidade e crenças no contexto brasileiro são marcadas pela sua complexidade, pluralidade, constante criação e recriação. Tratar dessa temática no contexto escolar requer uma postura ética, crítica e respeitosa por parte do educador para poder direcionar sua ação pedagógica e, consequentemente, contribuir com uma formação do estudante. Por esse viés 
O ensino religioso nas escolas públicas é assunto que exige atenção. Tema vinculado, em termos de direito, à liberdade de consciência e de crença, a presença plural das religiões no Brasil constitui-se fator de possibilidade de escolha. Ao indivíduo é dado o direito de ter religião, quando criança, por decisão de seus pais, ou, quando adulto, por escolha pessoal; de mudar de religião, por determinação voluntária ao longo da vida, sem restrições de ordem civil; e de não ter religião, como opção consciente. O que caracteriza, portanto, a inserção social do cidadão, desse ponto de vista, é o respeito, a abertura e a liberdade (BRASIL, 1997, p.30-1)

Independente da prática religiosa, o estudante carrega em si uma crença vinculada àquilo que acredita em relação às normas e valores sociais que se refletem nas ações diárias, no seu estar e situar no mundo. As crenças agregam valor e servem como modelos para a conduta moral, ética, social, enfim como norte para as ações diárias do estudante. 0 estudante-leitor religioso constrói sua leitura a partir de diferentes obras, dentre elas a Bíblia, livros devocionais e revistas - que são instrumentos com um valor simbólico religioso, que têm relação com o direito, liberdade de consciência e de crença, diversidade de manifestações e vivências da religiosidade na sociedade brasileira.

O leitor, assim como ocorre em todos os outros gêneros da literatura, não possui uma uniformidade na compreensão e na forma de perceber um texto bíblico ou outro texto literário que aborde temas que perpassem o campo religioso. Assim, dependendo da doutrina religiosa, a sua leitura levará a uma interpretação que terá um significado social e cultural percebido, independentemente de sua afiliação religiosa. No entanto, o sentido atribuído estará, estreitamente, relacionado às normas e dogmas da religiosidade que é adapto. Ou seja, o leitor de livros religiosos vai atribuir juízos de valor à obra lida a partir de suas crenças religiosas. Assim, um livro considerado excelente e inspirador para um, pode ser visto com reservas e preconceito por outros.

Ao ingressar no ambiente escolar o leitor "religioso" se defronta com a leitura literária e com uma nova exigência de si como leitor. Neste sentido, por a escola ser palco da diversidade e da diferença tem-se diferentes 
sentidos atribuídos à leitura literária devido às suas próprias crenças, que dependendo das matrizes religiosas e de alguns temas presentes na obra apresentam um caráter mais moralista, rígido, enquanto outras são mais abertas. Isso talvez se explique como sendo uma consequência das diversas doutrinas, das diferentes traduções bíblicas e dos variados livros doutrinais que se voltam para estudos específicos.

O conhecimento existente, suas crenças e sua forma de pensar e agir no mundo também poderão participar dessa nova formação, uma vez que o estudante é levado a discutir e pensar sobre diferentes assuntos do cotidiano social: criminalidade, violência, religião, política, guerra, sociedade, gênero, economia e se colocar diante desses assuntos não de forma passiva, mas como um agente crítico da realidade social. O pensar e a articulação crítica da leitura realizada exigem do estudante lançar mão dos conhecimentos que ele foi elaborando ao longo de sua existência, assim como de seus valores, sejam eles morais, éticos e religiosos que o constituem como sujeito, podendo ou não - nesse processo - deixar-se influenciar pelas suas crenças.

A partir dessa perspectiva, sugerimos que o professor de literatura do Ensino Médio deva apresentar obras literárias diferentes, que perpassem por épocas e contextos diversos, o que possibilita ao estudante refletir e usar a sua bagagem social, cultural e religiosa, proporcionando a interação entre os estudantes, numa perspectiva de educação intercultural no contexto de sala de aula.

É importante salientar que a obra literária não nasce com um caráter de formação de opinião ou de pensar o cotidiano, mas acaba desempenhando esse papel no momento que o sujeito-leitor reconhece nas entrelinhas elementos semelhantes ao seu cotidiano e que lança um olhar crítico para as temáticas que a perpassam.

Portanto, a partir da problematização da literatura como dispositivo para expressão de crenças religiosas na escola, a presente pesquisa tem o objetivo de verificar se as crenças se manifestam no contexto escolar no 
momento em que o estudante se depara com elementos da religiosidade nos textos literários.

Para atender a esse objetivo foram realizados os procedimentos metodológicos descritos na seção seguinte.

\section{Caminho Metodológico da Pesquisa}

Na busca para se verificar as "crenças religiosas" presentes no olhar do estudante-leitor, foram realizadas observações numa turma do Terceiro Ano do Ensino Médio, que tinha vinte e nove estudantes frequentes, de uma escola pública localizada no entorno do Distrito Federal, no Estado de Goiás.

Para fins de análise foram exploradas as falas de quatro estudantes, sendo um do sexo feminino e três do sexo masculino. Foi realizada observação in loco das aulas da professora e das expressões dos estudantes durante o desenvolvimento do letramento literário, com as obras "Tenda dos Milagres" e "Tieta do Agreste" ambas do escritor baiano Jorge Amado.

O momento de leitura e interpretação de obras literárias é relevante para os estudantes, ao possibilitar o desenvolvimento de um olhar crítico, constituição da consciência coletiva e novos sentidos. Quanto a isso, Cosson (2009) pontua que;

[...] na escola é preciso compartilhar a interpretação e ampliar os sentidos construídos individualmente. A razão disso é que, por meio do compartilhamento de suas interpretações, os leitores ganham consciência de que são membros de uma coletividade e de que essa coletividade fortalece e amplia seus horizontes de leitura. (COSSON, 2009, p. 65)

No trabalho do letramento literário a professora recorreu à proposta de Cosson (2006) para o Ensino Médio, com a articulação entre experiência, saber e educação literária. Assim, a professora inicialmente motivou a turma com a exibição de um trecho da novela Tieta do Agreste, exibida pela Rede Globo, preparando os estudantes para entrarem em contato com as obras a serem trabalhadas. Na sequência, fez a introdução mediante a 
apresentação do escritor Jorge Amado, observando-se que a turma já havia tido contato com algumas obras do referido escritor, entre elas, "Gabriela, cravo e canela"; "Dona flor e seus dois maridos"; "Tieta do Agreste" e "Tenda dos Milagres", essas duas últimas foram escolhidas pela turma para leitura e discussão.

Como primeira leitura foi selecionado o livro "Tenda dos Milagres", reservando-se um mês para realização da leitura. A turma deveria fazer a leitura extraclasse, podendo realizar esclarecimentos de dúvidas com a professora durante a semana. Na última semana do mês, os estudantes socializaram oralmente a interpretação da obra, fase denominada de "momento exterior" que consiste na "materialização da interpretação como ato de construção de sentido em uma determinada comunidade" (COSSON, 2009, p. 65).

Os mesmos procedimentos foram adotados para a leitura da obra "Tieta do Agreste", com acompanhamento das quatro aulas nas quais ocorreu a socialização da interpretação das obras, com registros das falas dos estudantes e professora, relacionadas com as temáticas crenças e religiosidade. Os dados extraídos são apresentados e discutidos a seguir.

\section{O Sincretismo Religioso nas Obras de Jorge Amado}

Jorge Amado nasceu numa fazenda de cacau em Itabuna - Bahia, em 10 de agosto de 1912. Passou a infância em llhéus, onde assistiu à luta entre fazendeiros e exportadores de cacau, que lhe inspirariam temas e tipos romanescos. Em Salvador, onde fez o curso secundário, ligou-se à Academia dos Rebeldes, grupo que, chefiado por Pinheiro Viegas, propunha uma literatura voltada para as raízes nacionais. Jorge Amado escreveu suas obras tendo como base a sua cultura, o seu cotidiano, o povo e os grandes problemas sociais vivenciados nas cidades baianas.

Ninguém contou melhor do que ele o mar, os becos e vielas, as ruas íngremes e os mistérios e magias da cidade da Bahia, 
espaço privilegiado na ficção amadiana. (Não há, portanto, qualquer dúvida de que a cidade é fonte de inspiração de escritores e desafio cotidiano de seus habitantes) (SILVA; PINHEIRO, 2004, p. 27).

Ao ler as obras de Jorge Amado, percebe-se uma aproximação entre o candomblé e a igreja católica em determinadas festividades populares, caminhando lado a lado pelos becos da Bahia. Talvez, hoje, no Brasil, Jorge Amado seja o autor que mais difundiu em suas obras essa fusão, pois foi capaz de perceber que as diferentes religiões participam ativamente das relações sociais. Como afirma Oliveira,

\begin{abstract}
Dentro das mais variadas culturas, o culto ao sobrenatural apresenta-se como fator de estabilidade social e de obediência às normas sociais. As religiões e as liturgias variam, mas o aspecto religioso é bem evidente. As pessoas procuram no misticismo e no sobrenatural algo que Ihes transmita paz de espírito e segurança. Por isso a religião sempre desempenhou uma função social indispensável. (OLIVEIRA, 2002, p. 169).
\end{abstract}

Assim como as obras literárias expuseram ao longo do tempo seu posicionamento social, o sagrado e o profano, muitas vezes, dividem o mesmo espaço e o que diferenciará um do outro é que o sagrado participa do particular, foge do cotidiano, diferente do profano, que é o cotidiano, o normal (ELIADE, 1992). Daí a junção de ambos nas obras de Jorge Amado. Por ser um autor que viveu em universo repleto de crenças, dissocia-las de sua obra seria algo quase impossível.

Para entender, no entanto, o sincretismo baiano, amplamente propagado pelo autor, só viajando na historicidade do Brasil, perpassando pela escravidão, que trouxe ao cenário nacional cultura, crenças e costumes que aos poucos foram se entrelaçando às demais culturas que compõem a sociedade brasileira. O pelourinho é um desses marcos onde se registra a história do Brasil, cenário das obras de Amado, sendo considerado O;

[...] lugar, onde correu o sangue dos escravos, é o território principal da parte da minha obra que tem como cenário a cidade de Salvador, a cidade da Bahia, como dizemos nós, os velhos baianos. Num dos casarões do Pelourinho transcorre a 
ação de Suor, nas suas ruas e ladeiras, no largo do Pelourinho Antônio Balduíno lutou boxe e Mestre Pastinha lutou capoeira, viveram aventura e poesia os Capitães da Areia, discutiram da vida e do amor Jesuíno Galo Doido, o negro Massu, Pede Vento, Curió e o Cabo Martim. Nas proximidades da igreja azul do Rosário dos Negros morreu Pedro Archanjo e ressuscitou Quincas Berro d'Água, e do alto da sua escadaria Tereza Batista, com o apoio de Castro Alves, que para tanto eu fiz descer do monumento para a luta do povo, Tereza Batista comandou a greve das putas da Bahia (AMADO, 2008).

Jorge Amado é um dos escritores brasileiros que descreve o povo, a geografia do Brasil, sua cultura e religiosidade, marcada por um grande sincretismo religioso que, na verdade, é a junção de doutrinas ou concepções religiosas de forma harmônica. $\bigcirc$ palco desses acontecimentos é o Estado da Bahia.

Analisando os aspectos da religiosidade na Bahia, a partir das obras de Jorge Amado, observa-se que ela é marcada pelos mistérios e segredos, sobre "o puro", "o legítimo", "o genuíno". Sua marca é a igualdade, com a qual trata santos católicos e orixás, o que se transforma, em seus romances, no mais concreto ato de sincretismo.

Nos enredos de Jorge Amado, homens e mulheres se sentem emponderados de uma força maior e se comportam como os deuses se comportariam se vivessem na terra. Por outro lado, narram sobre as características dos orixás e sua relação com o humano, que os alimentam no repasto dos ebós e giram em rodas feitas para rememorar - no transe das iaôs - suas míticas aventuras.

A obra "Tenda dos Milagres", de Jorge Amado, publicado em 1969 trata-se de um romance que aborda temas referentes à segregação racial na Bahia, especialmente em Salvador. Apresenta ainda o sincretismo religioso existente em nosso país, consequência das diferentes culturas que formaram o povo brasileiro.

Tem como personagem principal Pedro Archanjo, mestiço, pobre, um autodidata que dedicou parte de sua vida a estudar a antropologia, filosofia e sociologia. O que the chamava mais atenção era o povo simples, seus 
costumes e modo de vida. O estudante-leitor desse livro se depara com dois grandes contextos: o cultural e o religioso, assuntos constantes em rodinhas e nos dilemas sociais geradores de conflitos.

"Tenda dos Milagres" é uma narrativa de dupla temporalidade. De um lado, há um destaque ao ano de 1968, através das comemorações do centenário de Pedro Archanjo, personagem principal, tendo como contexto histórico o Brasil sob o regime político de exceção (Ditadura Militar), com todas as suas mazelas e contradições. E de outro lado, a pretexto de narrar a trajetória de vida de Pedro Archanjo (personagem central), a focalização do enredo centra-se no final do século XIX e nas primeiras décadas do século $X X$.

Alguns dos traços da religiosidade e crença presentes em "Tenda dos Milagres" podem ser observados no personagem Pedro Arcanjo, que é Ojuobá, os olhos de Xangô, o pai do povo deserdado da Bahia. Para isso, o escritor fez sua narrativa em dois tempos entrelaçados ao longo da história. O primeiro era o tempo presente (1869), onde relata a chegada de um estrangeiro no Brasil. O outro tempo, início do século XX, cujo foco está em Pedro Archanjo, um mestiço intelectual e autodidata, sem formação acadêmica, mas possuidor de amplo conhecimento de vida e da vida pelo convívio de seu povo.

Entre nós, o elemento português fez do africano e sua descendência a máquina inconsciente do trabalho, um instrumento de produção sem retribuir o esforço, antes o torturando com toda sorte de vexames. [...] Tem a via de pensar que esses homens sem instrução, mas só guiados pela observação e pela liberdade, foram os primeiros que no Brasil fundaram uma República, quando é certo que não havia naquele tempo tal forma de governo, nem dela se falava no país. (AMADO, 2008).

Outra obra clássica de Jorge Amado é "Tieta do Agreste", publicada em 1977 e que conta a história da protagonista Tieta, em Mangue Seco, divisa da Bahia com o Estado de Sergipe. Na trama, Mangue Seco recebe o 
nome fictício de Sant'Ana do Agreste. Nota-se neste texto uma grande preocupação ecológica que se torna nítida nos mais variados cenários.

Além da preservação ecológica, é possível refletir sobre várias outras temáticas a partir da leitura do livro, dentre elas a prostituição, o celibato, o significado do luto e o papel da igreja. Há cenas fortes, como a de Ricardo (o sobrinho de Tieta) acendendo velas contraditórias aos pés dos santos, intercedendo pela saúde da velha tia desconhecida:

Vida, doçura e esperança, a tia de São Paulo, que não esteja defunta como garante a mãe - a mãe vê tudo em luto -, que se afirme a crença da tia Elisa e o perigo desapareça, a vós bradamos os degredados filhos de Eva. A vós suspiramos e oferecemos pela saúde de tia Antonieta um rosário rezado de joelho sobre os grãos de milho (MONZATTO, 1994, p. 99).

\section{Expressões de Crenças Religiosas de Estudantes}

As obras "Tenda dos Milagres" e "Tieta do Agreste" de Jorge Amado podem ser um dispositivo literário de expressão de crenças religiosas de estudantes no contexto escolar. Ao trabalhar com as questões sobre as tradições e costumes religiosos pressupõe-se respeito às diversas expressões culturais, no sentido de construção do conhecimento e de significados.

Nesse sentido, buscou-se verificar as manifestações de crenças religiosas de estudantes, recorrendo à literatura como um dispositivo favorável à sua expressão. Com esse viés, a leitura e interpretação da obra "Tenda dos Milagres" realizada pelos estudantes demonstraram as crenças religiosas relacionadas à questão racial, assim como os sentidos atribuídos a elas pelos estudantes.

"Tenda dos Milagres" evidencia um enaltecimento da mestiçagem no Brasil, onde o negro (representado pelo personagem Pedro Archanjo) é visto com outro olhar, inclusive dentro da própria comunidade negra. Este personagem teve como elemento norteador de promoção social a religiosidade, que o colocou em evidência. 
Na discussão dessa obra, principalmente na centrada na trajetória de vida de Pedro Archanjo, observou-se que as crenças religiosas dos estudantes apareceram como um elemento sugestivo da igualdade de direitos entre as pessoas de diferentes origens étnicas. Essa alusão pode ser observada no comentário do Estudante 1, ao expressar que "O preconceito é a mais severa das atitudes do homem, contra sua própria raça, mostra que ainda precisamos evoluir muito espiritualmente, pois diante do Pai, todos somos iguais".

Analisando sua fala, percebemos que - para ele - a religiosidade ajuda na construção de conceitos sociais, sendo que a expressão "evoluir espiritualmente" denota inclinações ao pensamento espírita e suas ramificações. Por outro lado, esse relato sugere que a questão do preconceito racial ainda é um problema existente na sociedade brasileira, percebido pelos estudantes.

Pelo prisma da educação intercultural, a Estudante 2 aborda o direito de ser diferente na diversidade, o que requer a garantia do respeito à diferença entre as pessoas. "Não sou abrigada a seguir a religião de ninguém, mas respeito todas elas. Aqui na escola e lá fora tenho amigas católicas, evangélicas e espíritas e isso não mudou em nada" (Estudante 2).

Candau (2008) partindo da perspectiva intercultural para a educação, pontua os desafios na promoção de uma educação intercultural crítica e emancipatória, que articule questões relativas à igualdade e à diferença, defendendo;

[...] uma educação para a negociação cultural, que enfrenta os conflitos provocados pela assimetria de poder entre os diferentes grupos socioculturais nas nossas sociedades e é capaz de favorecer a construção de um projeto comum, pelo qual as diferenças sejam dialeticamente integradas. A perspectiva intercultural está orientada à construção de uma sociedade democrática, plural, humana, que articule políticas de igualdade com políticas de identidade. (CANDAU,2008, p.52). 
Assim, por ser a escola esse espaço plural, torna-se necessária a ampliação do debate no intuito de desconstrução da intolerância religiosa. Esclarecer e distinguir o que são expressões de intolerância religiosa em sala de aula passa a ser uma questão ética do profissional de educação, uma vez que no contexto de inclusão social, e principalmente escolar, é importante o respeito à diferença presente na diversidade cultural e religiosa existente no Brasil. A fala do Estudante 3 aproxima-se da ideia de uma sociedade intercultural na Bahia, onde católicos e seguidores do candomblé andam juntos.

A partir de questões visíveis no cotidiano dos estudantes, a exemplo das relações e interações entre pessoas de diferentes religiosidades, é possível desconstruir preconceitos naturalizados que muitas vezes passam despercebidos no contexto escolar. Nesse sentido, reafirma-se a importância de levantar e alimentar debates em sala de aula fortalecedor da construção de uma sociedade e educação intercultural, disponibilizando ferramentas intelectuais que levem a repensar práticas e discursos preconceituosos e intolerantes.

No trabalho com o romance "Tieta do Agreste", observou-se a expressão de crenças religiosas dos estudantes no momento da discussão. Dialogando sobre o personagem Ricardo, o Estudante 4 afirmou que "a oração é uma porta aberta do homem para Deus". Nessa discussão o Estudante 3 reafirma a expressão de crenças religiosas ao relatar que "há muita sinceridade na oração de Ricardo em prol da vida e saúde da tia".

As ideias religiosas e culturais também foram observadas ao ser abordada a relação amorosa da tia Antonieta (Tieta) e o sobrinho (Ricardo). A discussão sobre a temática do incesto e do celibato foram temas que tornaram as discussões efervescentes. Os estudantes adeptos das religiões protestantes, conhecidos como evangélicos, se posicionaram contra o celibato e o incesto.

A intolerância existente nas escolas frente às diversas religiões pode ser fortalecidas mediante práticas de professores, na maioria das vezes, não 
politizados. Os professores devem ser capacitados para mediar essas situações na sala de aula.

Muitas vezes a convivência entre esses grupos é marcada por preconceito e intolerância e cabe ao professor problematizar essas questões aos seus alunos e abrir horizontes para que o aluno possa perceber o diferente, demonstrando que não há a religião certa ou a errada, mas há a pluralidade religiosa. (XAVIER; FAGUNDES, 2011, p.3).

O Estudante 5 afirmou que "enquanto a igreja proibir o celibato, a pedofilia e a prostituição não deixarão de rondar seus altares". No entanto, a Estudante 2, adepta do catolicismo, relatou que "o celibato é um estado de pureza de alma". Essas visões demonstram que o celibato é visto de forma diferente, e talvez as normas e os dogmas seguidos pelas diferentes religiões influenciam esses distintos olhares.

O pensamento de Hervieu-Leger (2008), em relação ao papel que as religiões estão tendo no interior da sociedade contemporânea, nos permite perceber a dissolução das religiões como modelo homogêneo. O fato é que, nesse contexto, as subjetividades dos indivíduos se associam às crenças e, como consequência, migram pelas diferentes religiões, sem se prender a uma de fato.

Os diferentes olhares em torno do celibato demonstrados no contexto da pesquisa, corroboram essa ideia. Cabe pontuar que o argumento utilizado pelo Estudante 5 para sustentação do seu posicionamento contrário ao celibato esteve imbuído das crenças religiosas, utilizando-se de fragmentos contidos na Bíblia, conforme descritos a seguir.

É bom para um homem não ter relações sexuais com uma mulher. Mas, devido à tentação de imoralidade sexual, cada homem deve ter a sua própria mulher e cada mulher seu próprio marido (1 CO. 7. 1-2).

Eu desejo que todos sejam como eu sou. Mas cada um tem o seu próprio dom de Deus, um de uma espécie e uma de outro. Para os solteiros e as viúvas digo que é bom para eles permanecer como eu sou. Mas se eles não podem exercer autocontrole, devem casar. Por isso é melhor casar do que queimar com paixão. (PAULO, 1 CO. 7-9). 
A religiosidade pode ser um fator motivador e influenciador do posicionamento dos estudantes sobre diferentes assuntos que permeiam a sociedade. Nesse sentido, considera-se que a experiência religiosa, a fé está presente em diferentes tempos e que, independente da crença e da cultura, o homem busca respostas em algo que está além do visível, além da sociedade e das regras impostas pelo cotidiano; além da medicina e da ciência.

Ainda atreladas ao tema do celibato, ocorreram discussões sobre os personagens padres Inocêncio e Mariano, que geraram dois questionamentos, um em torno do o papel do padre na igreja e na sociedade, e outro sobre as implicações do estado civil no cumprimento do seu papel. Neste ponto, os estudantes refletiram sobre o papel de seus líderes religiosos e de suas ações dentro do contexto religioso ao qual estão atrelado e também na sociedade mais ampla.

Quanto a essa temática, Hervieu-Léger (2008) discutindo sobre a dissolução da religião diante de uma sociedade moderna, pontua os novos valores e formas de entendimento do religioso, do social e da própria crença, apontando que o líder religioso atual passa a ter uma conotação bem diferente dos líderes religiosos de outros tempos quando de fato a religião tinha um domínio social sobre todas as áreas, quando se vivia, no mundo, o paradigma religioso.

A liderança ainda permanece e exerce seu poder, mas muito restrita diante das diferentes manifestações religiosas presentes em nosso contexto. Se uma liderança não atende aos anseios buscados, logo se busca outra, até encontrar o que se procura ou que atenda à necessidade imediata. Daí a amplitude da palavra crença em um contexto tão complexo como o nosso e que - no contexto da pesquisa, com estudantes do Ensino Médio demonstrou que a literatura colabora para a expressão de diferentes ideias religiosas, sendo possível sugerir que os relatos e as ideias dos estudantes 
sobre os temas casamento, relacionamento e preconceito são influenciadas por suas crenças e vivências religiosas.

No contexto de sala de aula, o educador poderá conduzir os trabalhos docentes de forma que os educandos sejam capazes de extrair das leituras dos textos literários, dos vídeos e do material apresentado em sala, conexão entre as experiências oriundas da religiosidade com o dia a dia apresentado nos textos e no material. Poderá também refletir sobre a diversidade existente na comunidade onde ele está inserido, percebendo, pelo olhar do outro, que o que é visto com preconceitos por uns é sagrado para outros e, a partir disso, caminhar em direção à tolerância religiosa.

Os livros "Tenda dos Milagres" e "Tieta do Agreste" trabalhados em sala de aula serviram como ponte para que os estudantes pudessem trazer ao ambiente escolar suas leituras pessoais, construídas a partir de suas experiências religiosas e de vida, com influências e traços marcantes de sua cultura, de suas origens, de suas histórias familiares. Evidenciou-se que quando eram discutidos os aspectos da religiosidade nas obras literárias, cada um interpretava a experiência religiosa da obra a partir de sua própria história. Observou-se a influência da religiosidade, através dos sentidos atribuídos aos atos e vida dos personagens, que traduzem valores que marcam a identidade dos estudantes.

Os estudantes, na interpretação das obras, justificaram suas falas e defesa de sua tradição religiosa. Nesse contexto, a professora conduziu a discussão considerando a sala de aula como um espaço de diversidade, ressaltando que para se ter a garantia de direitos em meio à diversidade, o caminho é o respeito à diferença com relação ao outro. Na sala de aula, quando a religiosidade e as crenças foram colocadas em diálogo, mesmo os adeptos de religiões mais fechadas - como a protestante - demonstraram uma abertura e possibilidade de compreender a outra manifestação religiosa.

A partir desta leitura, é possível sugerir que esta pesquisa reafirmou a importância da literatura, por ser um dispositivo que contribui para que o 
estudante-leitor construísse diferentes olhares para as situações com demandas para um leitor proficiente. Os livros utilizados para a observação serviram derecursos pedagógicos para educação intercultural, desde que o professor considere, no processo de ensino e aprendizagem, os elementos da historicidade e da cultura do estudante compreendendo que ele se constitui enquanto pessoa na interação e relação com os elementos culturais e sociais aos quais está exposto.

Contudo, devido ao fato de a sociedade brasileira ter matrizes religiosas variadas, nas aulas podem vir à tona choques culturais ou conflitos religiosos. Essas diferentes religiosidades presentes e com implicações na leitura e interpretação das obras literárias reafirmam a ideia de que as crenças e a religiosidade não podem ser um tema ignorado, devendo ser tratados como um elemento positivador da pluralidade cultural existente na escola. As crenças construídas até essa fase podem permanecer ou mudar diante das relações com que o aluno-leitor lidará socialmente e continuarão interferindo na forma como ele vai agir diante da tomada de decisões que lhe serão impostas a todo o momento.

Atribuir valores, julgar, escolher, participar são ações que o sujeito estudado buscará fazer, levando sempre em consideração suas crenças, sua religiosidade, sua cultura, independente do que já se tenha apresentado como modelo a seguir. Até mesmo a curiosidade sobre a religião desconhecida pode ser de estimulador de novas conversas e pesquisas, sempre em direção ao caminho da diversidade. Conforme Martins (1994) ler não é simplesmente um aprendizado qualquer, mas uma conquista de autonomia, que permite a ampliação dos nossos horizontes, pois possibilita confrontar os conhecimentos existentes com novos que vão surgindo.

O leitor deve estabelecer uma relação dinâmica entre o que lê e a realidade que o cerca, sabendo de - forma reflexiva - estabelecer um olhar crítico sobre a ficção da literatura literária com as afirmações religiosas que fazem parte do seu cotidiano., travando um contado direto com variadas obras e com os diferentes olhares que possui sobre o mundo e sobre as 
relações que se estabelecem diante dos diferentes papéis sociais que cada um desempenha. Há uma participação ativa desse leitor, passando a ser um receptor que atua sobre o que lê, e não um mero espectador passivo.

Na construção da autonomia dos indivíduos, a escola passa a ser mais uma ponte durante a vida escolar, devendo desenvolver projetos voltados para leitura por se tratar de uma poderosa aliada contra intolerância religiosa, diferenças étnicas e culturais. Os textos literários poderão ser um dispositivo desse processo, contribuindo para a formação de cidadãos atuantes no seu contexto sócio, histórico e cultural.

\section{Considerações finais}

A literatura desperta o caráter subjetivo de expressão do homem, ajudando-o a perceber os diversos contextos sociais, colocando-o diante da possibilidade de analisar a cultura, os costumes, problemas, organização social e política; embora sem ter caráter obrigatório a construção da criticidade, o leva a um envolvimento com esse tipo de leitura. A escola é um contexto que possibilita a formação de leitores críticos e autônomos, capazes de desenvolver uma leitura crítica do mundo.

A pesquisa proposta teve o objetivo de verificar se as crenças se manifestam no contexto escolar no momento em que o estudante se depara com elementos da religiosidade nos textos literários. A partir das observações realizadas é possível sugerir que o estudante-leitor não tem consciência da presença delas, quando não é um elemento de análise interpretativa durante a leitura. Contudo, em suas interpretações e posicionamento diante dos fatos narrados é que elas se manifestavam, reconhecidas por símbolos, termos que o conduziam a um olhar diferente, fugindo do comum, indo além do esperado, nas entrelinhas do texto.

A busca da investigação era pela presença ou não de crenças religiosas nas obras e como elas contribuíam para uma reflexão mais profunda sobre as próprias ações, reconhecimentos de injustiças, 
preconceitos e principalmente de intolerância religiosa, comportamentos que foram criticados por esses leitores, o que foi plenamente alcançado.

A escola é um espaço de diversidade cultural e pode ser um local favorecedor de interação entre diferentes grupos religiosos e não religiosos. Aarte literária contribui com a educação intercultural, possibilitando um olhar crítico em relação à diversidade religiosa existente no contexto de sala de aula. A partir da perspectiva da educação intercultural percebe-se que o panorama religioso apresentado na escola em sua multiplicidade pode proporcionar o compartilhar de experiências e a riqueza de suas simbologias, - que evidencia as diversas faces do sagrado presentes em nossa sociedade.

A pluralidade das tradições religiosas na escola enriquece os estudos e investigações das religiões, como também se torna um desafio a uma compreensão do significado contemporâneo. No entanto, o grande desafio para a educação em nossos tempos marcado pela pluralidade religiosa é promover o respeito pelo outro como legítimo, em sua diferença e singularidade, sem o intento de homogeneizar as culturas, mas sim celebrar a diversidade cultural. É importante que as práticas educativas garantam "[...] o reconhecimento do outro, o diálogo entre os diferentes grupos socioculturais. Uma educação [...] orientada à construção de uma sociedade democrática, plural, humana, que articule políticas de igualdade com políticas de identidade" (CANDAU, 2008, p.54).

Através do letramento literário foi constatado que as obras literárias podem ser um dispositivo de expressão de crenças religiosas presentes no cotidiano da escola, assim como podem contribuir com a formação acadêmica do estudante-leitor. Reconhecer que com a literatura pode contribuir com a promoção da educação intercultural, ao valorizar as diferentes crenças é um passo fundamental para o diálogo inter-religioso. Exemplos das interfaces entre literatura e crença no espaço escolar, são os depoimentos captados durante a interpretação dos textos literários em sala de aula, ambiente que possibilitou exposição e análise das posturas e 
atitudes de personagens fictícios com os da vida real, do cotidiano de cada um.

É possível a participação das crenças na formação do estudanteleitor. No entanto, para que essas crenças tenham efetiva participação, a escola, enquanto lugar de trânsito de culturas, de encontros, de relações com múltiplas diversidades, precisa socializar o conhecimento histórico produzido pela humanidade, dentre os quais o religioso, que nos leva a conhecer várias entidades, simbologias, linguagens, valores e ritmos, utilizando como aporte a literatura como sinônimo de ficção. Poderia, no lugar, utilizar textos literários (a história do povo brasileiro), garantindo a liberdade religiosa dos cidadãos, como preceitua a Constituição Federal (BRASIL, 1988), mas não deixando de lado o seu papel de disseminar "saberes", que muitas vezes estão arraigados nos valores culturais, nos grupos religiosos e não religiosos.

Observou-se que as crenças e a religiosidade se constituem como elementos que influenciam os sentidos atribuídos pelos estudantes a diferentes temas, a exemplo do racismo, além de influenciar a construção e a revelação de uma concepção de mundo. Quando essa vem expressa em obras literárias, pode-se reconstruir o mundo dos significados subjetivos e definir, com referência a eles, os diversos fenômenos sociais.

\section{REFERÊNCIAS}

ABBAGNANO, Nicola. História da Filosofia. 6. ed. Lisboa: Editorial Presença, 1999.

AMADO, Jorge. Tenda dos milagres. São Paulo: Companhia das Letras, 2008.

AMADO, Jorge. Tieta do Agreste, Pastora de Cabras. 24. ed. Rio de Janeiro: Record, 2000.

SOCIEDADE BÍBLICA DO BRASIL. A Bíblia Sagrada: Antigo e Novo Testamento. Tradução de João Ferreira de Almeida. Edição rev. e atualizada no Brasil. Brasília: Sociedade Bíblia do Brasil, 1969. 
BRASIL. Secretaria de Educação Fundamental. Parâmetros curriculares nacionais: pluralidade cultural, orientação sexual / Secretaria de Educação Fundamental. - Brasília: MEC/SEF, 1997.

BRASIL. Constituição Federal de 1988. Promulgada em 5 de outubro de 1988. Disponível em http://www.planalto.gov.br/ccivil 03/constituicao/constituição.htm Acesso em: jan. 2017.

CANDAU, Vera Maria. Direitos humanos, educação e interculturalidade: as tensões entre igualdade e diferença. Revista Brasileira de Educação, v.13, n. 37, 2008. Disponível em: http://www.scielo.br/pdf/rbedu/v13n37/05.pdf Acesso em: jan. 2017.

COSSON, Rildo. Letramento Literário: teoria e prática. São Paulo: Contexto, 2009.

ELIADE, Mircea. O sagrado e o profano. Tradução Rogério Fernandes. São Paulo: Martins Fontes, 1992.

HERVIEU-Léger, Danièle. O peregrino e o convertido: a religião em movimento. Petrópolis: Vozes, 2008.

MARTINS, H. M. Leitura, saber e cidadania. Simpósio Nacional de Leitura. Rio de Janeiro: PROLER: Centro Cultural Banco do Brasil, 1994.

MARTINS, Maria Helena. O que é leitura? .19. ed. São Paulo: Brasiliense, 1994.

MANZATTO, Antonio. Teologia e literatura: reflexão teológica a partir da antropologia contida nos romances de Jorge Amado. São Paulo: Loyola, 1994.

OLIVEIRA, Pérsio Santos de. Introdução à sociologia. São Paulo: Ática, 2002.

SILVA, Antonieta Mirian de Oliveira Carneiro; SILVEIRA, Maria Inez Matozo. Leitura para fruição e letramento literário: desafios e possibilidades na formação de leitores. In.: VI EPAL. Anais, 2011.

SILVA, Maria Auxiliadora da; PINHEIRO, Délio José Ferraz. Visōes imaginárias da cidade da Bahia: diálogos entre a geografia e a literatura / organizadores. Salvador: UFBA, 2004.

XAVIER, Paula Martins; FAGUNDES Gustavo Henrique Godoy. Questões teórico- metodológicas no estudo das religiões e religiosidades. Revista Brasileira de História das Religiōes. Maringá (PR) v. III, n.9, Jan/201 1. Disponível em http://www.dhi.uem.br/gtreligiao/pub.html Acesso em: jan. 2016. 


\section{SOBRE OS AUTORES:}

\section{Elisângela Maura Catarino}

Doutora em Ciências da Religião, pela Universidade Católica de Goiás (PUCGO); professora do Centro Universitário de Mineiros; pesquisadora no Grupo de Pesquisa NEPEM/UNIFIMES e no Grupo de Estudo e Pesquisa em Psicologia, Neurociências e Educação (GEP-PNEdu). E-mail: maura@fimes.edu.br

\section{Marcelo Máximo Purificação}

Doutor em Ciências da Religião, pela Universidade Católica de Goiás (PUCGOIÁS); professor da Fundação Integrada Municipal de Ensino Superior (FIMES); Líder do Grupo de Estudo e Pesquisa em Psicologia, Neurociências e Educação Coordenador do Grupo de Estudos, Pesquisa e Extensão Multidisciplinar. E-mail: maximo@fimes.edu.br

\section{Maria Luzia da Silva Santana}

Doutoranda e Psicologia, pela Univeridade Católica de Brasília (UCB); professora da Universidade Federal de Mato Grosso do Sul (UFMS); líder do Grupo de Estudos e Pesquisa em Psicolobia, Neurociência e Educação. Email: santanapsi@gmail.com Aprovado em: 25 de setembro de 2017. 